\title{
The impact of land use and climate change in the centre region of France on the physico-chemical status of aquatic systems
}

\author{
Rachid Nedjai ${ }^{*}$ \\ ITP HCS - EA 1210 CEDETE Lab, \\ University of Orleans, France \\ Email: rachid.nedjai@univ-orleans.fr \\ *Corresponding author
}

\section{Van-Tuan Nghiem}

Vietnam National of Remote Sensing Department, Vietnam

Email: tuan.nghiem.rsc@gmail.com

\section{Thi-Phuong-Thao Do}

\section{LTHE Lab,}

Joseph Fourier University, France

Email: thao.do@ujf-grenoble.fr

\section{Messaoud Nacer Nasredine}

Institut d'Agronomie de Blida, Algeria

Email: n_messaoudnacer@yahoo.fr

\begin{abstract}
The impact of land use and climate changes on aquatic systems has been the topic of numerous scientific studies because many symptoms have been observed [flows disturbance, content organic carbon and nutrients $(\mathrm{P}, \mathrm{N})$ increase, rising of water temperature, generally accompanied by oxygen depletion, acidification and eutrophication]. The goal of this work is to show the direct impact of the land use change observed and climate change on the Loire watershed of France $\left(117,500 \mathrm{~km}^{2}\right)$, caused by a considerable reduction in farming activity over the past 30 years. The investigation of three dates of Landsat images (1985, 2000 and 2013) allows the detection of the closure landscape and the substitution of grassland by trees, especially in the high areas. Then, the WAMRF (hydrogeochimical model) is applied to calculate the water flows under these new land use and climate conditions. This first step is followed by a predictive phase prior to measuring the evolution of flows over the next 20 years. The results show a clear decrease of the flows during the simulation period (1985 to 2013) which is around $20 \%$ to the 2030 . In fact, these observations can be related to the enclosure landscape caused by the rural exodus and forest development registered in France since 1970 and the warming by climate change.
\end{abstract}

Keywords: land use; climate change; remote sensing; land change modeller; LCM; WARMF. 
Reference to this paper should be made as follows: Nedjai, R., Nghiem, V-T., Do, T-P-T. and Nasredine, M.N. (2016) 'The impact of land use and climate change in the centre region of France on the physico-chemical status of aquatic systems', Int. J. Spatial, Temporal and Multimedia Information Systems, Vol. 1, No. 1, pp.102-117.

This paper is a revised and expanded version of a paper entitled 'The impact of land use change on the quality of water under the climate change: example of Loire river' presented at the Geomatic Conférence of Orléans France, France, July 2014.

\section{Introduction}

France, as well as other European countries, recorded significant changes in its population on demographic plans and especially mutations. Indeed, agricultural areas have indicated an important evolution of land use over the last 30 years, in particular for the remote areas. The stigmas of the evolution in 1960s were confirmed. It was due to mostly by changes in vegetation plan that gradually moves from the farmland to the forest areas. These changes were accompanied by the gradual closure of landscapes, which usually marked by a colonisation of forest species (conifers, deciduous, ...). In parallel, urban areas, especially large cities have an important development.

In plain region, it is especially the exodus of rural areas that account for a large part of these phenomena. Faced with this dynamic, managers indicate that the current management tools are still not enough to address the issues due to lack of means of forecasting for future trends.

However, all conclusions are consistent with a disruption of the hydrological and chemical dynamics of ecosystems. These affect the environment on both the abiotic and biotic component: reduction of benthic fauna of water bodies, higher levels of organic matter and deoxygenation and finally imbalance of hydrological dynamics.

To measure the degree of disturbance and the impact of land use change on the hydrological dynamics, using the remote sensing and geomatic provides a way unequivocal to predict this change and their connection with hydrological models that allow quantifying the potential imbalance of the water resource.

We therefore propose to use the module land change modeller (LCM) of IDRISI-Taiga Software for modelling the land use evolution.

The results of this prediction of land use will be introduced in a hydrogeochemical model to reconstruct chronic flow in outlet of the Loire watershed. The chronic analysis used to estimate variances and therefore the degree of disturbance of the hydrological dynamics of the Loire.

Further, the impacts of land use change on river basin hydrology are interlinked with impacts of climate change. Observed climatic changes in France include warming from 0.7 to $1.0^{\circ} \mathrm{C}$ following regions and decreased precipitation for the West of France over the period 1901 to 2000 (ONERC, 2012). Future projections by the Intergovernmental Panel on Climate Change (IPCC) include warming from 0.5 to $1.5^{\circ} \mathrm{C}$ and around $-10 \%$ decrease in precipitation by 2030 to 2050 (ONERC, 2012; IPCC, 2007). 
Overall, in the Loire watershed, annual temperature is projected to increase and annual mean rainfall is projected to decrease during the first part of the century (Artelia, 2013).

The simulated flow regimes under different scenarios of change allow creasing an effective planning of water resource use and protection under changing conditions of the basin.

The main purpose of this study is to assess the sensitivity of land use and climate changes on the water flux of the Loire River in France.

For this purpose, scenarios of land use change are developed based on trends and information from the results of LCM model using the land use maps of 1985, 2000 and 2013, and climate change predictions are considered based on the IPCC (2007). The results of this research provide a decision support system for integrating watershed management; they also provide an evaluation of the application of hydrogeochemical models such as the WARMF for large watersheds.

\section{Methodologies}

\subsection{Study area}

The Loire watershed has an area of $117,000 \mathrm{~km}^{2}$ that is more than $20 \%$ of France (Figure 1). It is an agricultural and a little urbanised basin where include main cities such as Nantes, Angers, Tours, Orleans and Saint-Etienne (Leprieur et al., 2008).

Figure 1 Geographic extent of the Loire watershed (see online version for colours)

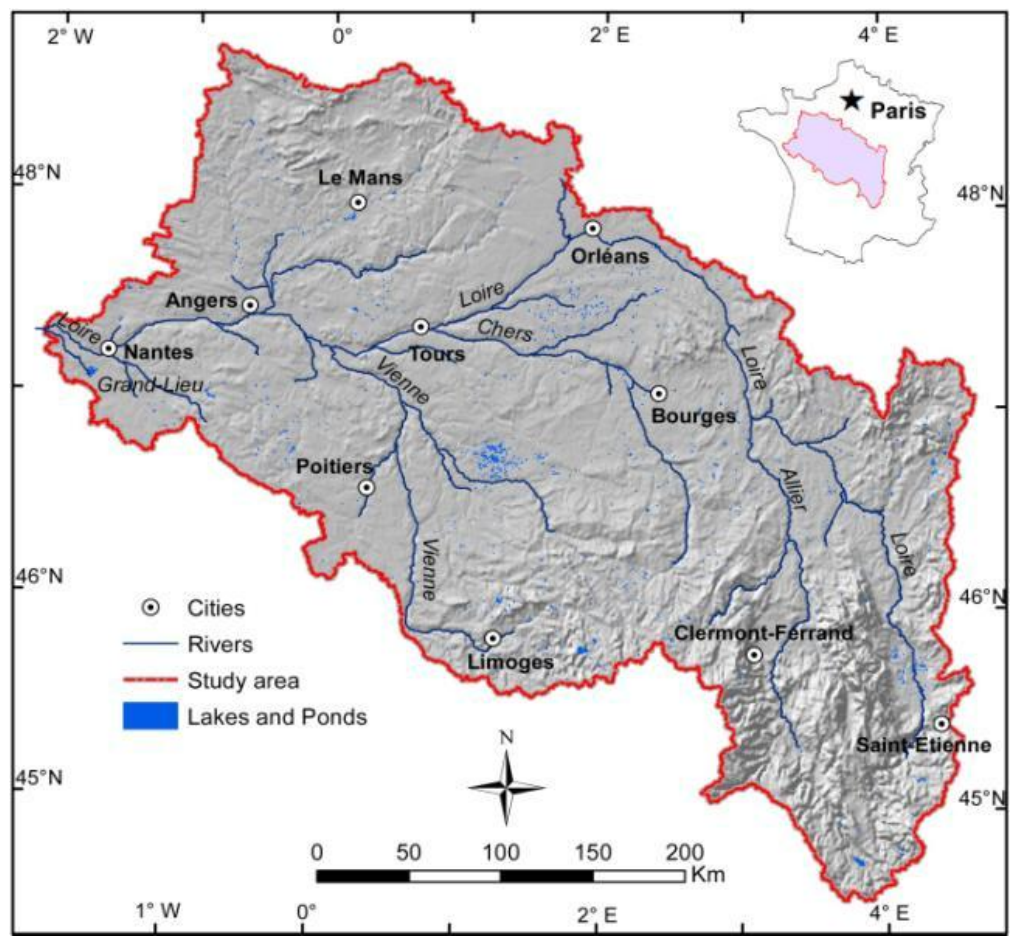


With the length of more than $1,000 \mathrm{~km}$, the Loire is the longest river in France. It rises in the highlands of the south-eastern quarter of the Massif Central in the Cevennes range at 1,350 m near Mont Gerbier de Jonc.

The river flows first to the north across the Massif Central, and then turns to the northwest through Nevers to Orleans and the southwest after Orleans. Eventually, it flows into the Bay of Biscay (Atlantic Ocean) through an estuary located at Saint-Nazaire (Loire-Atlantique).

\subsection{LCM: land use change prediction}

This modelling is based on the principle of Markov chains, such as in equation (1) (Weng, 2001) to predict the future land use of the Loire watershed for the next 15 years.

$$
P\left\{X_{t}=a_{j} \mid X_{0}=a_{0}, X_{1}=a_{1}, \ldots, X_{t-1}=a_{i}\right\}=P\left\{X_{t}=a_{j} \mid X_{t-1}=a_{i}\right\}
$$

where $X_{0}, X_{1}, \ldots, X_{t-1}$ are the observed values of the Markov chain in the discrete-time $(0,1,2, \ldots, t-1)$.

The matrix $P\left\{X_{t}=a_{j} \mid X_{t-1}=a_{i}\right\}$ is known as the transition probability and indicates the probability that the process makes a transition from state $a_{i}$ to state $a_{j}$ after a period of time $(t)$.

Several assumptions are issued for the application of Markov chains, one of which is to consider land use and its change as a stochastic process, and the different categories are the states of a Markov chain (Haan, 1977; Stewart, 1994; Griffiths, 2010; Mubea et al., 2010).

\subsection{Model WARMF: hydrological dynamics evaluation of the basin}

The WARMF model is a decision support system for the integrated management of water resources in large watersheds. It is capable of simulating the water quantity and quality. It is an independent model where a dedicated block modelling incorporating the main hydrological and hydrochemical equations, a data management system and a graphical model dedicated to the display of results (Chen et al., 2001; Herr et al., 2001). WARMF has five modules (data, engineering, knowledge, TMDL and consensus) integrated easily accessible via a graphical user interface (GUI). These modules can work independently each other or together. The application of WARMF model can be divided into four stages:

1 data preparation

2 sub-basin delineation

3 model calibration

4 scenarios analysis.

\subsubsection{Data preparation}

Table 1 presents the data needed for modelling flow of the Loire watershed. Many of them were collected from services and administrations of the Loire and Bretagne watersheds, the water agency. Other data that we can consider as internal are issued from 
different treatments performed by us on the basis of data collected over several international websites (DEM, Images Landsat, ...).

\subsubsection{Mapping land use data}

We used 36 scenes of Landsat images covering the entire Loire watershed: 12 scenes of Landsat4 TM (1985), 12 scenes of Landsat7 ETM + (2000) and 12 scenes of Landsat8 OLI_TIRS (2013). All these images correspond to the same dry season (June to August), to avoid possible errors of classification due to seasonal variation of vegetation. They are also in the same spatial resolution $(30 \mathrm{~m})$. However, due to the heterogeneity of the acquisition dates, spectral resolution images, angle and the rotation of images, a preprocessing before classification was made to reduce the potential differences between the images. For this, three steps are necessary: geometric correction, atmospheric correction and mosaic. In this case, the atmospheric correction methods of Chander and Markham (2003), Ruelland et al. (2008) and Richter and Schlaepfer (2014) are used for TM, ETM + and OLI_TIRS images, respectively.

Table 1 Data used in the WARMF model

\begin{tabular}{lcc}
\hline Data & Data source & Date \\
\hline DEM (30 m) & Aster-DEM (http://www.jspacesystems.or.jp) & 2013 \\
Soil map & Soil Map of France (Roque, 2007) & 2007 \\
Land use & Landsat5 TM (USGS, http://earthexplorer.usgs.gov/) & 1985 \\
& Landsat7 ETM (USGS, http://earthexplorer.usgs.gov/) & 2000 \\
& Landsat8 OLI_TIRS (USGS, http://earthexplorer.usgs.gov/) & 2013 \\
Meteorology & Météo-France (http://www.meteofrance.com) et Global & $1985-2013$ \\
& Weather Data (http://globalweather.tamu.edu) & $1985-2013$ \\
Flows & Banque Hydro (http://www.hydro.eaufrance.fr) &
\end{tabular}

Then, a quality evaluation of the samples was carried out on the basis of calculating the separability index between the image spectrums (ITT Inc., 2008). Two indices were used, namely the transformed divergence (TD) and Jeffries-Matusita (J-M) (Richards and Jia, 2006). They vary in the interval from 0 to 2 . The higher values of these indices indicate better separability.

To generate land use maps, the method of supervised classification using the maximum likelihood algorithm was used. For the purpose of this study, categories of three land use maps generated for the study area are:

1 deciduous

2 conifers

3 mixed forest

4 farmland

5 prairies

6 built-up area

7 water. 
Figure 2 illustrates the land use map of 2013 after the supervised classification.

After the classification for the three land use maps (1985, 2000 and 2013), a phase of accuracy estimation is needed to evaluate the deviations with respect to the results of field observations and auxiliary data. Two indices are used to evaluate the accuracy, the global accuracy and Kappa coefficient. It will be considered acceptable or satisfactory if the global accuracy reaches or exceeds 85\% (Anderson, 1971). The results of accuracy calculation for the three maps after the image classification are summarised in Table 2. The global accuracy exceeds $86 \%$ and the values of Kappa coefficients are greater than 0.85 , thus confirming the validity of the classification and the acceptable results.

Figure 2 Land use map classified from 2013 images (see online version for colours)

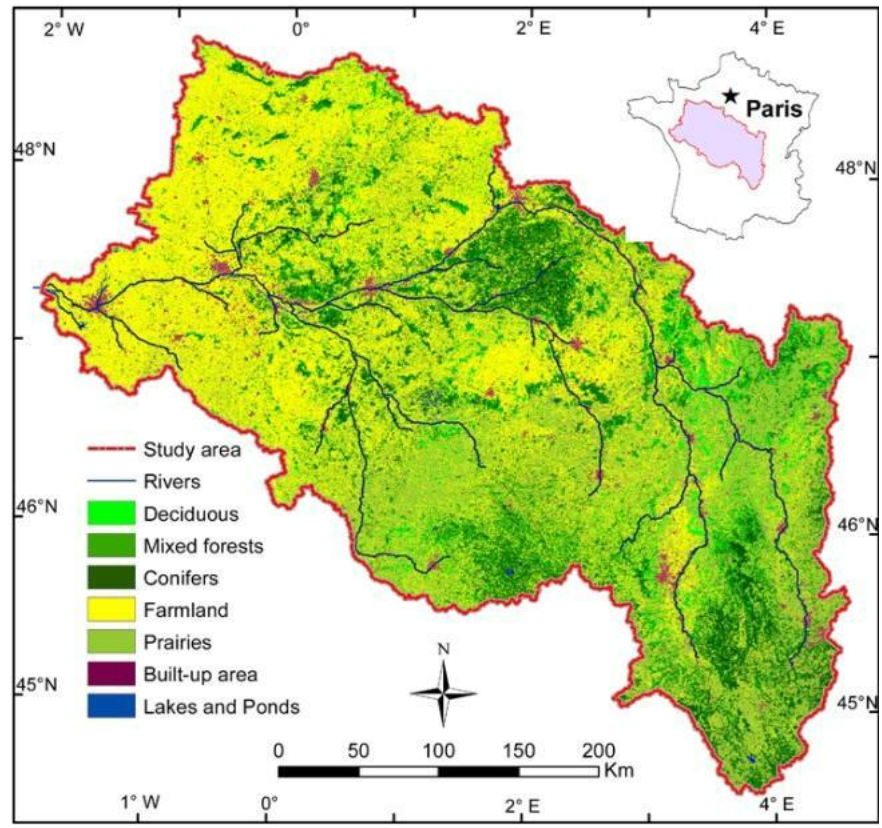

Table 2 Accuracy calculated for the three land use maps

\begin{tabular}{lccc}
\hline Dates & 1985 & 2000 & 2013 \\
Accuracy (\%) & 86.71 & 89.23 & 89.54 \\
Kappa & 0.85 & 0.89 & 0.90 \\
\hline
\end{tabular}

\subsubsection{Climate data}

Climate data used in the WARM model consist of daily rainfall, temperature max, temperature min, wind speed, dewpoint, cloudcover, and atmospheric pressure data. The used weather variables were the daily precipitation, minimum and maximum air temperature, wind speed values obtained from the Global Weather Data (http:/globalweather.tamu.edu) for 30 stations for the period of 1985 to 2010. The atmospheric pressure and dewpoint values obtained from the MéteoFrance for the same period. The cloud cover data was calculated from the minimum and maximum air 
temperature, dewpoint and precipitation data using the following approach (Systech Engineering, 2007):

$$
d T=A B S\left[\frac{\left(T_{\min }+T_{\max }\right)}{2}-T_{\text {Tdew }}\right]
$$

where $T_{\min }=$ minimum temperature $\left({ }^{\circ} \mathrm{C}\right), T_{\max }=$ maximum temperature $\left({ }^{\circ} \mathrm{C}\right)$, Tdew $=$ dewpoint temperature $\left({ }^{\circ} \mathrm{C}\right)$.

Then, the $d T$ value was compared with the precipitation data to determine the cloud cover values, example:

AND IF Precip $=0$ THEN

IF $d T<4$ THEN Cloud $=0.6$.

\subsubsection{Soil data}

The WARMF model requires soil property data for the different layers of each soil type (Chen et al., 2001). Each soil layer has its own area, thickness, field capacity, saturated moisture content, horizontal conductivity, and vertical conductivity. Soil data were obtained from the Soil Map of France of 1/100,000 (Roque, 2007). The most widespread soil type in the Loire Watershed consists: brown soils, brown calcareous soils, leached soils, degraded soils, rendzina soils, hydromorphic soils, alluvial soils, peat soils, podzols and sealed soils.

\subsubsection{Observed flow data}

The observed flow data was obtained for the Loire River from the 'Loir à Nantes' station (M6240010) located at the outlet of the basin. The observed flow values for the Loire River were used for calibration and validation of the model. The available flow data for the Loir à Nantes station ran from the year 1985 to the year 2013.

\subsubsection{Sub-basin delineation}

Topography is a necessary input in the WARMF model and is used in the delineation of the sub-basin and analysis of the land surface characteristics (width, long, slope, aspect, etc.) and drainage patterns (width, depth, slope, etc.). It influences the rate of movement and direction of flow over the land surface (Shrestha et al., 2008). The digital elevation model (DEM) of $30 \mathrm{~m}$ of resolution from the GDEM of ASTER was used in this analysis.

\subsubsection{Model calibration and validation}

Model calibration is performed by modifying the parameters of the WARMF model. The main parameters used for hydrology calibration are shown in Table 3. The model calibration was performed over the period 2004 to 2013, with the first two years, 2006 and 2007 dedicated to the stabilisation of the model. The simulated flows during the period from 2008 to 2013 were used for comparison with the observed flows from the 
records of the Hydro Bank (Eaufrance). Statistical measures such as the Nash-Sutcliffe coefficients, determination $\left(\mathrm{R}^{2}\right)$, percentage $\mathrm{pBias}$, and the total volume error are used to assess the accuracy rate of the flow simulation in the phase calibration.

Table 3 Parameters used in the WARMF calibration

\begin{tabular}{lc}
\hline Parameters of soil layers & Parameters of basin \\
\hline Soil density & Snow formation temperature \\
Vertical cond. hydraulic & Snow melting temperature \\
Field capacity & Snow melting rates \\
Horizontal cond. hydraulic & Slope \\
Saturation moisture & Precipitation weighting \\
Root distribution & Manning's n \\
Soil thickness & Detention storage \\
\hline
\end{tabular}

\subsection{Hydrologic evolution: scenario analysis}

\subsubsection{Generation of land use scenarios}

Many land use prediction models such as LCM, Markov chain, CA-Markov and GEOMOD, considered effectively for the predicting land use change, due to their coupling GIS and their potential of ecological simulation, have been developed (Eastman., 2009; Pontius and Chan, 2006; Tewolde and Cabral, 2011; Pijanowski et al., 2002). The LCM module integrated in the Idrisi-Taiga software (Eastman, 2009) is used for assessing the land use change of Loire watershed. This module allows to identify the gradual transition from one land use category to the others as a sequential treatment giving rise, and final, to give both graphs and maps. This increases the capacity to assess the land use changes and can provide a prediction of the land use data for the next 20 years (Nghiem et al., 2013). The transition assessment is based on the integration of static and/or dynamic variables, called explanatory, such as the network of road and river, DEM, slope, aspect, precipitation, soil types, etc. In order to predict the land use change in the medium term, the integration of variables, called planning reinforces and/or forcing potential changes is carried out.

To calculate the probability of occurrence for each transition, the LCM model provided two options: logistic regression (LogReg) that takes into account the changes and potential explanatory variables (Kleinbaum and Klein, 2002) and multi-layer perceptron (MLP) neural network which assesses the nature of the relationship between transitions and the explanatory variables

Several studies have shown that the MLP can provide good results with an accuracy rate of predictive maps greater than 85\% (Dadhich and Hanaoka, 2010; Nghiem et al., 2013). In addition, the MLP method shows some advantages: MLP requires less data (Atkinson and Tatanall, 1997; Martinuzzi et al., 2007; Dadhich and Hanaoka, 2010), the volume calculation is less important than for the LogReg, and it is the best in the modelling of transitions (Eastman, 2009). Therefore, using the MLP method is a reasonable choice for our study. 
In this study, the reference maps of 1985 and 2000 were used in order to create the land use map to 2013 of the Loire watershed, by using the Markov chains. This phase is to evaluate the performance of the LCM model in the land use prediction.

For calibration and validation of LCM model, a comparative analysis between the prediction map and reference map after processing satellite images for the same date by using the confusion matrix. This matrix is based on the relationship between the number of correctly classified pixels and the total number of pixels of the image (Chuvieco et al., 2002). Then, potential errors based on each model, omission and commission errors are evaluated. To evaluate the overall accuracy of the predictive map, the accuracy rate and Kappa index will be also used (Pontius et al., 2001).

In this study, the accuracy rate of predictive map to 2013 exceeds $89 \%$ and Kappa index varies around 0.90 , thus confirming the good fit of the predicted results and the proper calibration of the model. These results allow to generate the land use scenarios to 2020 and 2030 based on the previously explanatory variables which were selected for each transition. For example, Figure 3 illustrates the land use map to 2030.

Figure 3 Land use map predicted to 2030 (see online version for colours)

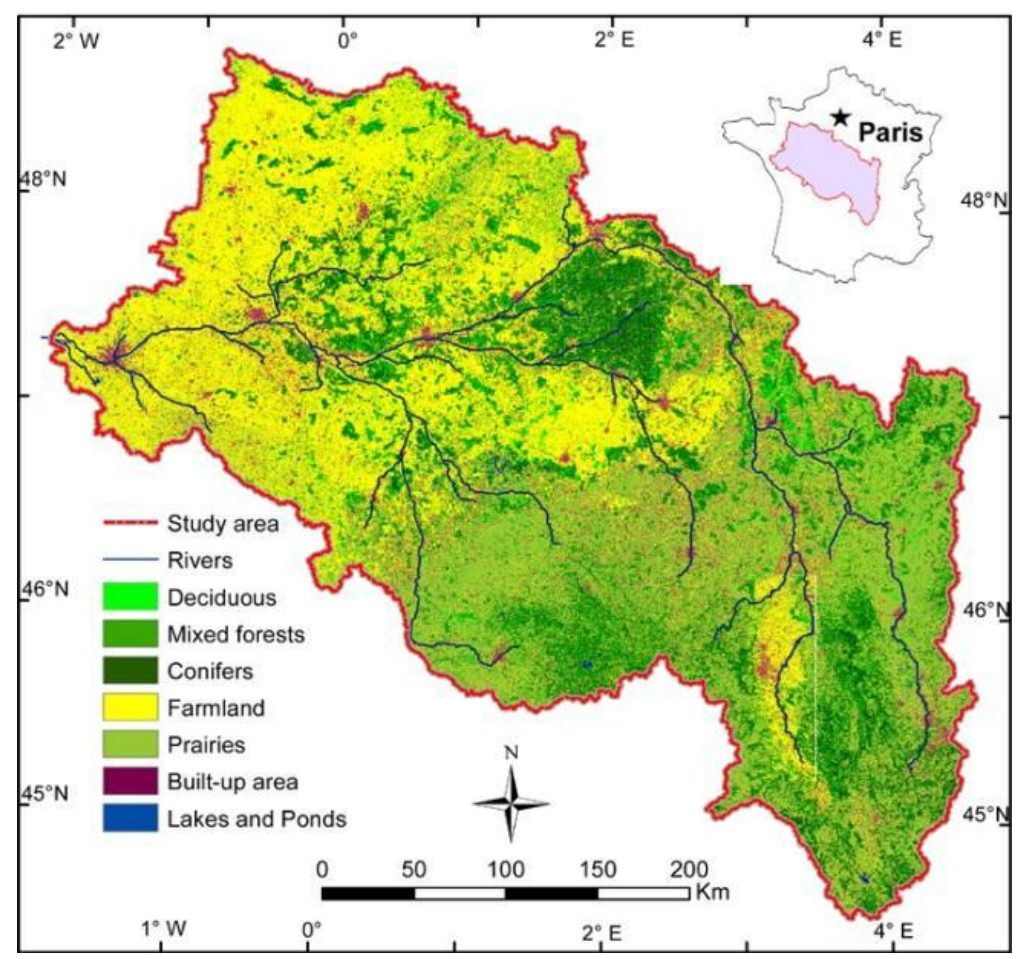

Diachronic analysis of land use of 2013, 2020 and 2030 shows relatively dynamic contrasts. Indeed, farmland and meadows recorded a relatively moderate increase between 2013 and 2020, and very high between 2013 and 2030. Conversely, forest land and urban areas increased very significantly (Table 4 ). 
Table 4 Land use changes over the period 2013-2030

\begin{tabular}{|c|c|c|c|c|c|c|c|}
\hline \multirow{2}{*}{ Categories } & \multicolumn{3}{|c|}{ Land use $\left(\mathrm{Km}^{2}\right)$} & \multicolumn{2}{|c|}{ Evolution $\left(\mathrm{Km}^{2}\right)$} & \multicolumn{2}{|c|}{$\begin{array}{c}\text { Rate of evolution } \\
(\%)\end{array}$} \\
\hline & 2013 & 2020 & 2030 & $\begin{array}{c}2013- \\
2020\end{array}$ & $\begin{array}{c}2013- \\
2030\end{array}$ & $\begin{array}{c}2013- \\
2020\end{array}$ & $\begin{array}{c}2013- \\
2030\end{array}$ \\
\hline Deciduous & $8,200.36$ & $8,541.12$ & $9,185.96$ & 340.76 & 985.60 & 4.16 & 12.02 \\
\hline Conifers & $4,362.30$ & $4,560.14$ & $4,960.14$ & 197.84 & 597.84 & 4.54 & 13.70 \\
\hline $\begin{array}{l}\text { Mixed } \\
\text { forest }\end{array}$ & $15,485.17$ & $17,139.69$ & $18,589.05$ & $1,654.52$ & $3,103.88$ & 10.68 & 20.04 \\
\hline Farmland & $43,184.01$ & $39,857.86$ & $36,341.38$ & $-3,326.15$ & $-6,842.63$ & -7.70 & -15.85 \\
\hline Prairies & $36,116.94$ & $35,549.68$ & $35,148.61$ & -567.26 & -968.33 & -1.57 & -2.68 \\
\hline $\begin{array}{l}\text { Built-up } \\
\text { area }\end{array}$ & $7,965.00$ & $9,672.38$ & $11,095.73$ & $1,707.38$ & $3,130.73$ & 21.44 & 39.31 \\
\hline
\end{tabular}

\subsubsection{Climate change scenarios}

The climate change scenarios for this study were based on downscaled from climate projections produced by Meteo France (Artelia, 2013), built from the IPCC (2007). The main points of climate analysis in the Great West to 2030 are following:

- The annual average temperatures will increase between 0.8 and $1.4^{\circ} \mathrm{C}$ compared to the average temperature of reference (reference period: 1971 to 2000). This increase is more pronounced in summer, with temperature anomalies up to $1.8^{\circ} \mathrm{C}$ by 2030 on the Vendee, Loire Atlantic and the Morbihan.

- A moderate decrease in mean annual rainfall and an increase of drought episodes may occur. This increase can be from 10 to $30 \%$ of the time in a state of drought, with peaks up to $40 \%$.

Synthesis from the above results allows us to propose a scenario of climate change to adapt for the Loire watershed to 2030. For this scenario (2A), the expected temperature will increase to $1.5^{\circ}$ and precipitation will decrease by $10 \%$

\section{Result and discussion}

\subsection{Model calibration}

The calibration phases were carried out on the basis of data collected from services hydrometric monitoring of the Loire watershed. The calibration results confronted with observed data show that the anomalies are relatively low at the beginning of simulations and higher at the end of the simulation period (Figure 4).

The Nash-Sutcliffe efficiency between simulated and observed flows varies around 0.80 and the $\mathrm{R}^{2}$ coefficient is 0.75 . The volume error $(7.16 \%)$ is in the acceptable range of $+-10 \%$ (Table 5). 
Table 5 Statistical evaluations of the daily flows simulation of the Loire River (at Nantes)

\begin{tabular}{lcc}
\hline Parameters & Calibrated values & Recommended value \\
\hline $\mathrm{R}^{2}$ & 0.75 & $0.5-1.0$ \\
Nash-Sutcliffe & 0.86 & $0.5-1.0$ \\
Volume erros (\%) & 7.16 & $-1+10$ \\
pBias (\%) & 20.45 & $-25 \mathrm{à}+25$ \\
\hline
\end{tabular}

Figure 4 Flow calibration for Loire River (at Nantes) (see online version for colours)

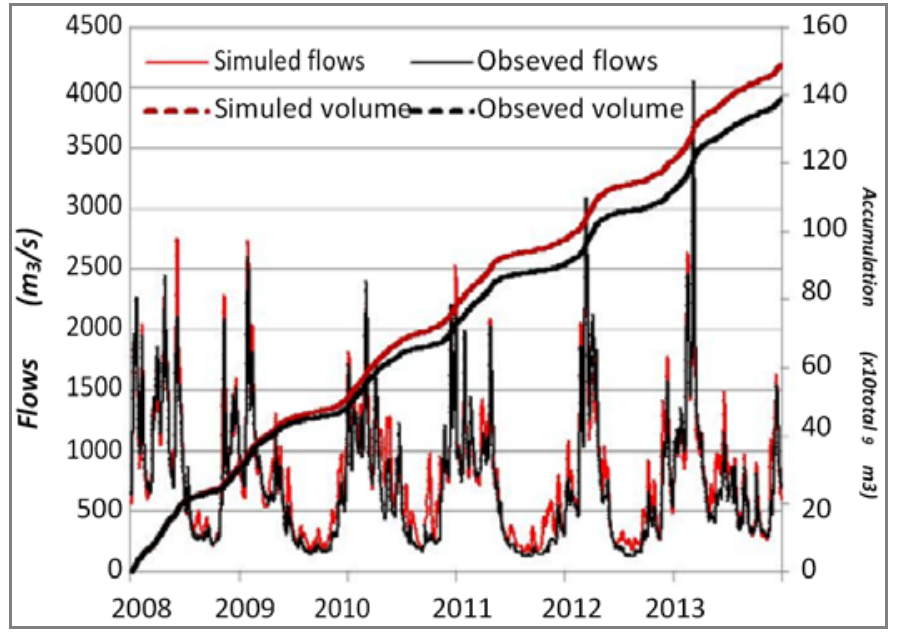

\subsection{Effects of land use changes on hydrology}

The analysis of the flow evolutions at Nantes (outlet of the Loire River) are shown in Figure 5. Curves 'baseline', '2020s' and '2030s' present the simulated flows and corresponding volumes, respectively, to the land use of 2013, 2020 and 2030. Several observations can be made from reading this figure:

- A flow decreases are recommended for the future resulting in more pronounced variations following the seasons. These variations may be due to changes in forest areas. This phenomenon is mainly due to the interception and consequently increasing the retention capacity of water by trees during the rainy season, and the increase of evapotranspiration during the dry season. Indeed, the presence of a dense canopy hinders greatly the flow of water to the ground by an interception process which retains a fraction of rainfall. This fraction is likely then to evaporate more quickly during the dry season and less rapidly during the rainy season (Bultot et al., 1972; Aussenac, 1975; Dumas, 2009). For example, the analysis of the relationship between precipitation and the amount of water reaching the ground in forested areas of the Massif de la Chartreuse, showed that the variability of interception under the canopy depends on rainfall intensity (Dumas, 2009). The interception rate is highest for very low rainfall, and conversely. 
- The lines of the mean monthly flows of the Loire at Nantes, for the different land use states of 2013, 2020 and 2030 show that the flows for land use to 2030 fall sharply during the summer season (May to October). A maximum decrease of the mean monthly flows, estimated at $10.6 \%$, was recorded in September. This can be explained by the fact that forests are still green during this month which has a highly rainfall interception (month of very low rainfall, about $40 \mathrm{~mm}$ ).

- Comparison between the mean monthly flows for the land use of 2013 and those for the land use to 2020 and 2030 shows a relative stable during the higher rainfall periods (January-March and October-December). Although the monthly rainfall recorded relatively high levels during these periods (about $90 \mathrm{~mm}$ ), the anomalies of the mean monthly flows between baseline and land use of 2030s did not exceed $1 \%$. This can be explained by the fact that during the winter period (January-March) and autumn (October-November), deciduous have lost their leaves, and thus cannot intercept rainfall.

Figure 5 Flow evolutions of the Loire River (at Nantes) due to land use change (see online version for colours)

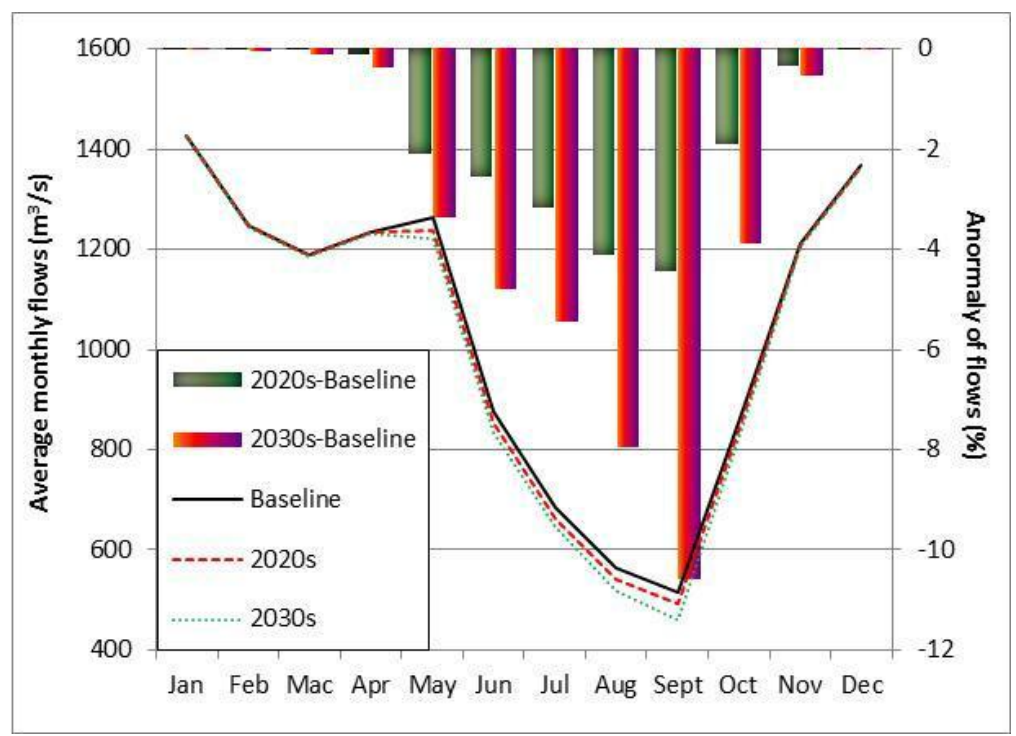

\subsection{Combined effects of land use and climate changes on the hydrological dynamics}

Concerning the land use change of the Loire watershed, the land use scenarios in this paper showed that the forest areas has clearly developed over the past 30 years and will continue if no action is implemented. Moreover, the study results of Artelia (2013) showed that climate change will affect this watershed, thereby confirming the close relationship between the two phenomena, even the causal effect between them. Therefore, the Loire watershed will be doubly affected in the future.

Under the effect of the land use change, our results show that this change has a significant impact on the hydrology evolution of the Loire watershed. In this section, we 
try to evaluate the combined effects of land use and climate change on the hydrological dynamics for this watershed. For this, a scenario (2B) consists of two different scenarios (land use and climate changes) will be used. The amendment will one hand on land use predicted to 2030 , and the two main climatic parameters, i.e., temperature will be increased by $+1.5^{\circ} \mathrm{C}$, and precipitation will be reduced by $-10 \%$.

Figure 6 and Table 6 have the dual impact of land use and climate changes on the flows in the Loire watershed.

Figure 6 shows that the scenario $2 \mathrm{~B}$ has a more pronounced effect on the hydrological dynamics than on climate scenario $(2 \mathrm{~A})$ and the land use scenario.

Figure 6 Combined effect of land use and climate changes on the hydrology of the Loire (at Nantes) (see online version for colours)

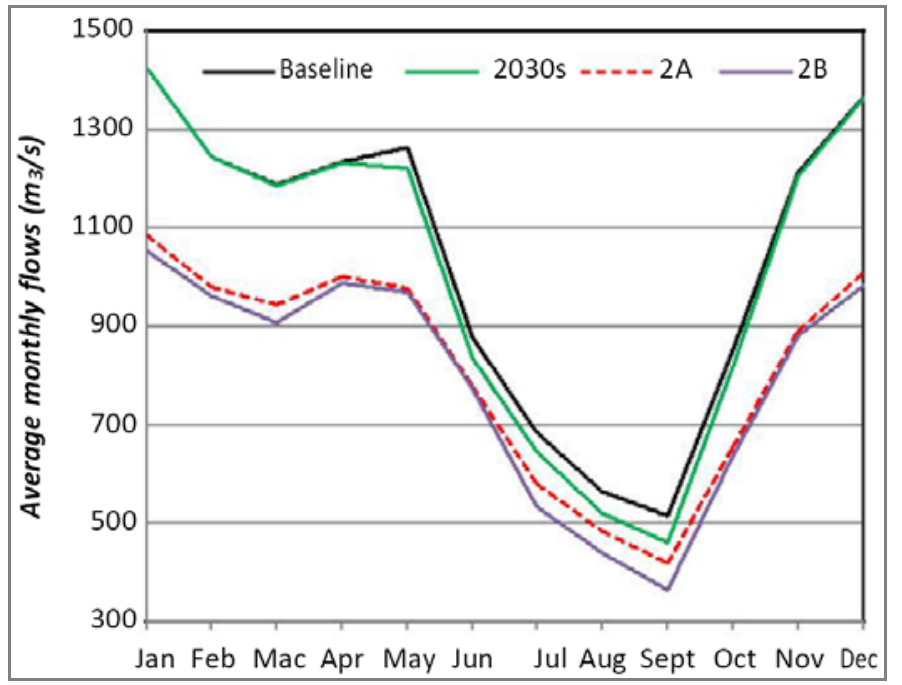

Table 6 Flow dynamics due to land use and climatic changes of the Loire watershed

\begin{tabular}{|c|c|c|c|c|c|c|c|}
\hline \multirow{2}{*}{ Date } & \multicolumn{4}{|c|}{ Flows $\left(\mathrm{m}^{3} / \mathrm{s}\right)$} & \multicolumn{3}{|c|}{ Anomaly (\%) } \\
\hline & Baseline (BL) & $2030 s$ & $2 A$ & $2 B$ & $2030 s-B L$ & $2 A-B L$ & $2 B-B L$ \\
\hline January & $1,425.58$ & $1,425.37$ & $1,084.05$ & $1,053.86$ & -0.01 & -23.96 & -26.08 \\
\hline February & $1,246.24$ & $1,245.55$ & 980.64 & 961.43 & -0.06 & -21.31 & -22.85 \\
\hline March & $1,187.98$ & $1,186.52$ & 945.18 & 908.11 & -0.12 & -20.44 & -23.56 \\
\hline April & $1,235.74$ & $1,231.31$ & 999.88 & 987.52 & -0.36 & -19.09 & -20.09 \\
\hline May & $1,264.27$ & $1,221.80$ & 977.10 & 969.95 & -3.36 & -22.71 & -23.28 \\
\hline June & 877.11 & 835.06 & 778.18 & 772.95 & -4.79 & -11.28 & -11.88 \\
\hline July & 683.00 & 645.65 & 579.33 & 531.98 & -5.47 & -15.18 & -22.11 \\
\hline August & 564.31 & 519.45 & 484.13 & 438.27 & -7.95 & -14.21 & -22.33 \\
\hline September & 514.03 & 459.53 & 419.64 & 364.14 & -10.60 & -18.36 & -29.16 \\
\hline October & 853.34 & 820.12 & 656.37 & 636.31 & -3.89 & -23.08 & -25.43 \\
\hline November & $1,212.98$ & $1,206.57$ & 891.71 & 880.51 & -0.53 & -26.49 & -27.41 \\
\hline December & $1,366.47$ & $1,366.15$ & $1,008.41$ & 983.95 & -0.02 & -26.20 & -27.99 \\
\hline
\end{tabular}


Table 6 shows a significant decrease in the mean monthly flows for the September $(-29.16 \%)$ which is higher than that induced by the land use change $(-10.60 \%)$, and the only climate change $(-18.36 \%)$ for the same period. For the scenario $2 \mathrm{~B}$ (combination), the average annual flow can decrease by $-23.51 \%$, which is significantly greater than those of the $2030 \mathrm{~s}$ and $2 \mathrm{~A}$ scenarios, with the respective decreases of $-3.10 \%$ and $-20.19 \%$.

Finally, the combined impact of land use and climate changes can cause very significant reductions of flows for the Loire watershed. The causes of these reductions originate from the reduced precipitation and increased evaporation, especially due to the highly interception of the deciduous.

\section{Conclusions}

The use of remote sensing, GIS and their coupling with the hydrological models offer a reliable way to predict the dynamics of basins on hydrology, chemicals or even biology. France, like many experience countries a mass exodus of rural populations leaving large areas fallow. This accelerates the process of recolonisation by species evolved first by shrubs and then gradually by trees. We have also noted the extent of the phenomenon in mountainous areas where conifers (spruce essentially) accompanied by deciduous arrive to fill the space formerly occupied by grasslands or by agriculture. Using the remote sensing and processing of several satellite missions of the Loire watershed confirms this trend and the integration of different land use maps in a Raster GIS (Idrisi) for the purposes of predictive modelling shows that this trend is sustainable.

Hydrological modelling on the Loire watershed shows a tendency to reduced flows in the different outlets of watersheds and particularly in Nantes, main outlet of the Loire River. This dynamic tends to increase in the future under the leadership of global climatic phenomena. The integration of different climate scenarios from the IPCC confirms rising water shortages especially during the summer. The months of July-August and September are the most affected by the phenomena.

\section{References}

Anderson, J.R. (1971) 'Land use classification schemes used in selected recent geographic applications of remote sensing', Photogramm.Eng., Vol. 37, No. 4, pp.379-387.

Artelia (2013) Stratégie d'adaptation au changement climatique dans le Grand-Ouest, Artelia Eau \& Environnement Unité Climat Energie, 53pp.

Aster-DEM [online] http://www.jspacesystems.or.jp (accessed November 2014).

Atkinson, P.M. and Tatanall, A.R.L. (1997) 'Neural networks in remote sensing', International Journal of Remote Sensing, Vol. 18, No. 4, pp.699-709.

Aussenac, G. (1975) Couverts forestiers et facteurs du climat: leurs interactions, conséquences écophysiologiques chez quelques résineux, Univ. Nancy, 234pp (Thèse Doct. Sci. Nat.).

Banque Hydro [online] http://www.hydro.eaufrance.fr (accessed February 2014).

Bultot, F., Dupriez, G. and Bodeux, A. (1972) 'Interception de là pluie par la végétation forestière; estimation de l'interception journalière à l'aide d'un modèle mathématique', $J$. of Hydrol., Vol. 17, No. 3, pp.193-223. 
Chander, G. and Markham, B.L. (2003) 'Revised Landsat-5 TM radiometric calibration procedures and postcalibration dynamic ranges', IEEE Transactions on GeoScience and Remote Sensing, Vol. 41, pp.2674-2677.

Chen, C.W., Herr, J. and Weintraub, L. (2001) Watershed Analysis Risk Management Framework (WARMF): Update One. A Decision Support System for Watershed Analysis and Total Maximum Daily Load Calculation, Allocation and Implementation, Topical Report, Systech Engineering, 163pp.

Chuvieco, E., Martin, M.P. and Palacios, A. (2002) 'Assessment of different spectral indices in the red-near-infrared spectral domain for burned land discrimination', Int. J. Remote Sensing, Vol. 23, No. 23, pp.5103-5110, Taylor \& Francis Group.

Dadhich, P.N. and Hanaoka, S. (2010) 'Markov method integration with multi-layer perceptron classifier for simulation of urban growth of Jaipur City', Selected topics in Power Systems and Remote Sensing, pp.118-123, ISSN: 1792-5088, ISBN: 978-960-474-233-2.

Dumas, D. (2009) 'Estimation de l'influence de la couverture forestière sur les pluies en montagne: exemple du massif de la Chartreuse', Revue Forestière Française, Vol. 60, No. 6, pp.711-726.

Eastman, J.R. (2009) IDRISI Taiga: Guide to GIS and Image Processing, Clack Lab-Clack University, Manual version 16.02, p342p.

Global Weather Data [online] http://globalweather.tamu.edu (accessed June 2014).

Griffiths, R.B. (2010) 'Stochastic processes', Lecture Notes on Quantum Mechanics, No. 8, qmc082.tex, Version of 30 September, p.1-10.

Haan, C.T. (1977) Statistical Methods in Hydrology, The Iowa State University Press, Ames, Iowa.

Herr, J., Weintraub, L. and Chen, C.W. (2001) User's Guide to WARMF: Documentation of Graphical User Interface, EPRI Final Report, EP-P2346/C1054, 185pp., Published by Systech Engineering, Inc.

Intergovernmental Panel on Climate Change (IPCC) (2007) Climate change 2007: The Physical Science Basis. Contribution of Working Group I to the Fourth Assessment Report of the Intergovernmental Panel on Climate Change, The 10th Session of Working Group I of the IPCC, Paris, February.

Intergovernmental Panel on Climate Change (IPCC) [online] http://www.ipcc.ch/ (accessed February 2007).

ITT Inc. (2008) ENVI Online Help, Version 4.5, ITT Corporation, USA.

Kleinbaum, D.G. and Klein, M. (2002) Logistic Regression: A Self-Learning Text, 2nd ed., 516pp. With Contributions by Erica Rihl Pryor. Series Editors: K. Dietz, M. Gail, K. Krickeberg, J. Samet and A. Tsiatis, Springer.

Leprieur, F., Chaptal-Gradoz, N., Chitry, F., D'Amico, D. and Debayle, C. (2008) 'La mesure de la radioactivité dans le bassin versant de la Loire: Acteurs, réseaux, inventaire des données', Rapport de l'Institut de Radioprotection et de Sûreté Nucléaire (IRSN), Publié par le Direction de l'Environnement et de l'Intervention, 116pp.

Martinuzzi, S., Gould, W.A. and González, O.M.R. (2007) 'Land development, land use, and urban sprawl in Puerto Rico integrating remote sensing and population census data', Landscape and Urban Planning, 2 March, Vol. 79, Nos. 3-4, pp.288-297.

Météo-France [online] http://www.meteofrance.com (accessed March 2014).

Mubea, K.W., Ngigi, T.G. and Mundia, C.N. (2010) 'Assessing application of Markov chain analysis in predicting land cover change: a case study of Nakuru municipality', JAGST, Vol. 12, No. 2, pp.126-144.

Nghiem, V-T., Nedjai, R., Le, V-A. and Charleux, L. (2013) 'Application of GIS and remote sensing for predicting land-use change in the French Jura Mountains with the LCM model: the impact of variables on the disturbance model', Proceeding of the 34th Asian Conference on Remote Sensing, Bali, Indonesia, pp.2588-2595, ISBN: 978-602-9439-33-5, (SC04-95 à SC04-102). 
Observatoire national sur les effets du réchauffement climatique (ONERC) (2012) Plan national d'adaptation de la France aux effets du changement climatique. Rapport au Premier ministre et au Parlement. Version pour une diffusion électronique, Edition assurée par La documentation Française, p.80.

Pijanowski, B.C., Brown, D.G., Manik, G. and Shellito, B. (2002) 'Using neural nets and GIS to forecast land use changes: a land transformation model', Computers, Environment and Urban Systems, Vol. 26, No. 6, pp.553-575.

Pontius Jr., R.G. and Chen, H. (2006) GEOMOD Modeling: Land-Use \& Cover Change Modeling, Idrisi 15: The Andes edition, Clark Labs, Worcester, MA, 44pp.

Pontius Jr., R.G., Cornell, J. and Hall, C. (2001) 'Modeling the spatial pattern of land-use change with Geomod2: application and validation for Costa Rica', Agriculture, Ecosystems \& Environment, Vol. 85, Nos. 1-3, pp.191-203.

Richards, J.A. and Jia, X. (2006) Remote Sensing Digital Image Analysis, p.454, Book of Springer-Verlag, Berlin, Heidelberg.

Richter, R. and Schlaepfer, D. (2014) Atmospheric/Topographic Correction for Satellite Imagery: ATCOR-2/3 User Guide, Version 8.3.1, DLR IB 565-01/13, Wessling, Germany, 238pp.

Roque, J. (2007) Carte pédologique de France à 1/100 000, ISBN: 978-2-7380-1248-7, INRA.

Ruelland, D., Dezetter, A. et al. (2008) 'Long-term monitoring of land cover changes based on Landsat imagery to improve hydrological modelling in West Africa', International Journal of Remote Sensing, Vol. 29, No. 12, pp.3533-3551, Taylor \& Francis.

Shrestha, M.S., Artan, G.A., Bajracharya, S.R. and Sharma, R.R. (2008) 'Using satellite-based rainfall estimates for streamflow modeling: Bagmati Basin', J. Flood Risk Manage., August, Vol. 1, No. 2, pp.89-99.

Stewart, W.J. (1994) Introduction to the Numerical Solution of Markov Chains, Princeton, NJ.

Systech Engineering (2007) Creating a WARMF 6.2 Application: Using a BASINS 3.1 Delineation. A User's Guide, pp.19-24.

Tewolde, M.G. and Cabral, P. (2011) 'Urban sprawl analysis and modeling in Asmara, Eritrea', Journal of Remote Sensing, Vol. 3, No. 10, pp.2148-2165, doi:10.3390/rs3102148.

USGS [online] http://earthexplorer.usgs.gov/ (accessed 2015).

Weng, Q. (2001) 'Land use change analysis in the Zhujiang Delta of China using satellite remote sensing, GIS and stochastic modelling', Journal of Environmental Management, Vol. 64, No. 4, pp.273-284, Elsevier. 